\title{
EXPERIMENT AND NEURAL NETWORK MODEL OF PRIMARY FRAGMENTATION OF OIL SHALE IN FLUIDIZED BED
}

\author{
ZHIGANG CUI, XIANGXIN HAN, XIUMIN JIANG*, \\ JIANGUO LIU
}

Institute of Thermal Energy Engineering, School of Mechanical Engineering Shanghai Jiao Tong University, Shanghai 200240, P. R. China

\begin{abstract}
In this paper, the effect of fluidized bed temperature on primary fragmentation of Huadian oil shale was investigated experimentally in thermal state using a small-scale fluidized bed with $\mathrm{N}_{2}$ as fluidizing gas. The fluidized-bed temperatures changed from $600{ }^{\circ} \mathrm{C}$ to $1000{ }^{\circ} \mathrm{C}$. Experimental results indicate that the fluidized bed temperature is an important factor of primary fragmentation of oil shale, and that higher bed temperature results in severer fragmentation. The laminated structure and high ash content may contribute to the primary fragmentation characteristics of Huadian oil shale. The thermal stress fragmentation and devolatilization-induced fragmentation have little effect on small oil shale particles. Furthermore, the experimental data were treated by a neural network method, and a Back Propagation network model for primary fragmentation of oil shale was set up through network learning and validated by experimental data.
\end{abstract}

\section{Introduction}

To improve the availability of oil shale, many specialists recommend burning oil shale in circulating fluidized beds (CFBs), which produce satisfactory combustion efficiency, low $\mathrm{NO}_{\mathrm{x}}$ and $\mathrm{SO}_{2}$ emission, adaptability to low-grade coal, appropriate capital and operation costs, etc. [1-5]. After oil shale particles are plunged into a fluidized bed (FB), severe primary fragmentation and secondary fragmentation will occur, which have great effect on bed materials' concentration and particle size distribution referring to combustion ratio, heat transfer in furnace, distribution of heat load, etc. In addition, the fragmentation can also play a role in desulfurizer utilization efficiency, separator design and abrasive wear of heating surface.

Primary fragmentation is usually defined as the breakage of fuel particles into smaller particles during devolatilization, and it is mainly caused by

\footnotetext{
* Corresponding author: e-mail xiuminjiang@ sjtu.edu.cn
} 
thermal stress because of the fast heating rate and the internal pressure built up by the volatile matter in the pore network [6-8]. Primary fragmentation occurs before combustion begins, then secondary fragmentation takes place during the post-devolatilization combustion of char particles [9]. Many researches of the fragmentation of fuel during combustion have been carried out and the cause of fragmentation has been analyzed. Using a high-temperature drop-tube furnace, Dacombe et al. [10] examined the fragmentation nature of large (1-4 mm) granular anthracites and bituminous coal particles and found that the number of fragments tends to reduce with time for smaller particles, while the number of fragments remains high for larger particles. They also found that the extent of fragmentation increases with increasing furnace temperature and particle size. Lee et al. [11] studied primary fragmentation and particle size reduction of anthracite coal during devolatilization, with the result that the fragmentation increases with increasing devolatilization temperature and particle size. Two processes, fragmentation and swelling, can cause change in large particle diameter in a relatively short period, mainly during devolatilization of coal [12]. Abdelmounaim et al. [13] studied thermal pre-treatment effect on the fragmentation of oil shale solid particles from Tarfaya deposit (Morocco), processed in a fluidized-bed combustor. It was found that fragmentation rates were experimentally estimated to increase as high as 3-5 times once shale was preheated. AlOtoom et al. [14] found that there was very small number of fragmentations of Jordanian oil shale particles occurring during combustion or ashing in a laboratory furnace in the studied range of oil shale particle size $(<0.15 \mathrm{~mm})$. They suggested that the stagnant conditions of the experimental combustion process may also help the phenomenon.

After being crushed for the demand of combustion in an industrial oil shale-fired FB boiler, Huadian oil shale exhibited laminated structure because of its self-affinity in physical properties [2]. In order to understand the primary fragmentation characteristics of oil shale particles with laminated stucture, the experiment of the primary fragmentation of Huadian oil shale in a lab-scale fluidized bed was conducted. Since the primary fragmentation process is determined by many factors such as physical and thermal properties of oil shale, bed temperature and other operating conditions, and is so complicated that it is a nonlinear system, the experimental results obtained at different bed temperature were analyzed by a neural network method, and a neural network model for the primary fragmentation of oil shale during fluidized bed was set up through network learning.

\section{Experimental}

The oil shale sample was obtained from Huadian, China. Its ultimate and proximate analysis is given in Table 1 . 
The lab-scale FB system used in the experiment is shown in Fig. 1. It consists of a fluidized bed, an automatic temperature controller and a gas supply system. The fluidized bed is made of a stainless-steel tube $(50 \mathrm{~mm}$ diameter, $400 \mathrm{~mm}$ height), and its distributor grid is a stainless-steel net with 200 meshes. Bed materials are quartz sand particles in the size range $0.5 \mathrm{~mm}-0.6 \mathrm{~mm}$.

Experimental conditions were: fluidized bed temperature was 600,650 , $700,750,800,850,900,1000{ }^{\circ} \mathrm{C}$, respectively; particle size distribution of oil shale plunged into the FB is consistent with that generally used in industrial oil shale-fired FB boiler, as shown in Fig. 2, and its mass content

Table 1. Proximate and ultimate analysis of Huadian oil shale

\begin{tabular}{|l|c|c|c|}
\hline \multicolumn{2}{|c|}{ Proximate analysis } & Ultimate analysis, mass\%, ad \\
\hline Moisture, mass\%, ad & 2.90 & $\mathrm{C}$ & 31.63 \\
Volatile matter, mass\%, ad & 41.89 & $\mathrm{H}$ & 4.37 \\
Ash, mass\%, ad & 51.61 & $\mathrm{O}$ & 7.76 \\
Fixed carbon, mass\%, ad & 3.60 & $\mathrm{~N}$ & 0.73 \\
Net calorific value, $\mathrm{kJ} \cdot \mathrm{kg}^{-1}, \mathrm{ad}$ & 8374 & $\mathrm{~S}$ & 1.00 \\
\hline
\end{tabular}

ad - air dry basis

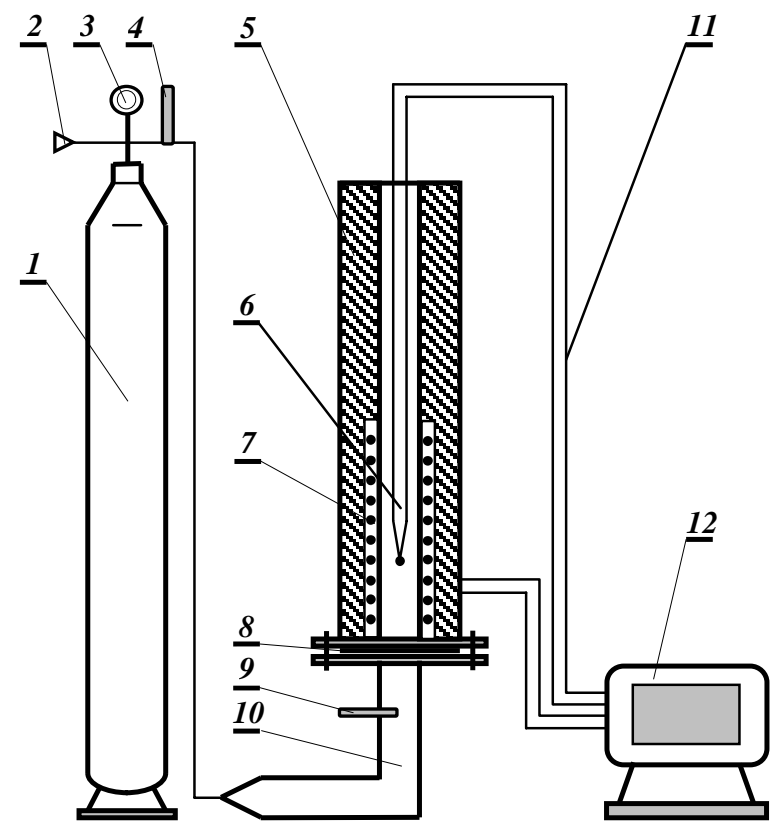

Fig. 1. Block diagram of the fluidized-bed system: 1 - gas cylinder, 2 - flow control valve, 3 - manometer, 4 - flowmeter, 5 - refractory, $\mathbf{6}$ - fluidized bed, 7 - electric heater, 8 - distributor grid, 9 - thermometer, 10 - gas box, 11 - thermocouple, 12 automatic temperature controller. 


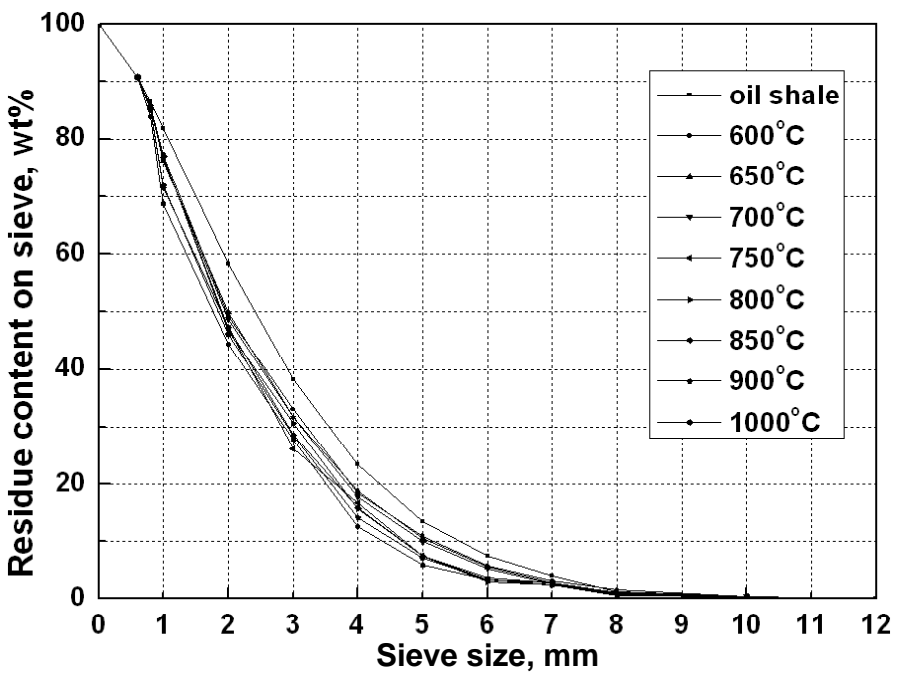

Fig. 2. Particle size distribution of shale chars at different fluidized bed temperatures.

was $5 \mathrm{wt} \%$ of all the materials (oil shale and bed materials) which was $50 \mathrm{~mm}$ in height; $\mathrm{N}_{2}$ was used as fluidizing gas to avoid any possibility of combustion during the primary fragmentation process, and fluidizing velocity was $0.8 \mathrm{~m} / \mathrm{s}$ for keeping the bed in the turbulent fluidizing regime.

When the FB was initially heated to a desired temperature by the temperature controller, a red light was on and an electric heater switch tripped off so that the resistance wire stopped working, in the mean time oil shale samples prepared were plunged into the bed and subsequently crackles can be heard, indicating that severe fragmentation of oil shale particles was occurring there. After the bed temperature was maintained for $120 \mathrm{~s}$ by the automatic temperature controller, power and $\mathrm{N}_{2}$ supply switch would be shut off, and shale char and quartz sand particles were poured out and covered rapidly and fully with cold quartz sand particles $(0.5-0.6 \mathrm{~mm})$ and cooled to the normal temperature. At last, the materials were sieved to separate quartz sand particles and shale char was obtained and analyzed in the particle size distribution.

\section{Results and discussion}

Figure 2 shows the particle size distribution of shale chars obtained at different fluidized bed temperatures, showing that the particle size distribution of shale chars submits approximately R-R distribution. Figure 3 gives the change of the median size of these shale chars with increasing bed temperature. Based on the Fig. 2 - Fig. 3, it is concluded that the fluidizedbed temperature is an important factor of oil shale primary fragmentation, and that higher fluidized-bed temperature results in severer fragmentation. 


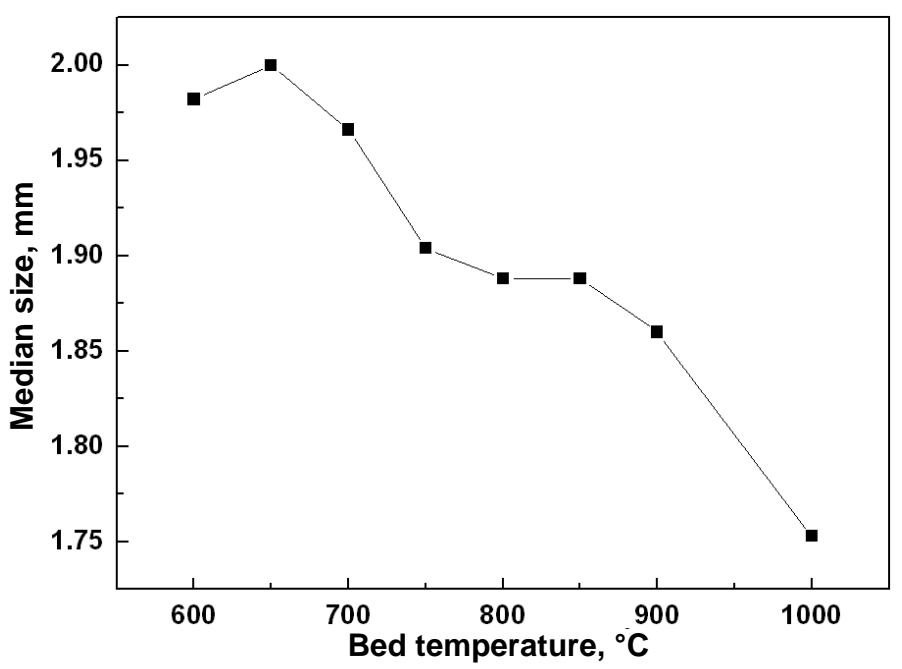

Fig. 3. The median size of shale chars with increasing bed temperature.

It is usually recognized that primary fragmentation consists of thermal stress fragmentation and devolatilization-induced fragmentation. Oil shale particles plunged into the fluidized bed are heated rapidly by the scorching bed materials in turbulent fluidizing status, which forms a large temperature gradient within the particles. On the other hand, due to rapid heating rate, much volatile matter released from oil shale particles cannot give off out of the particles in a short time, which can build up a high internal pressure within the particles. When the stresses caused by both the temperature gradient and the internal pressure within the particles are larger than tensile failure strength of the oil shale particles, the primary fragmentation can occur. When the fluidized-bed temperature is higher and, consequently, the volatile matter is formed more and more faster, the yielding stresses within the oil shale particles will subsequently increase greatly, and so the primary fragmentation happens more easily.

Compared with the primary fragmentation extent of several coals [9], that of Huadian oil shale is not marked, which could be explained by the fact that Huadian oil shale has laminated structure and contains large proportions of ash (51.61\% on air-dry basis). The high proportions of ash are expected to maintain the original structure of the oil shale particles [14]. In addition, the fragmentation of oil shale particles with laminated stucture follows the selfaffine behavior in the fracture developing and fragmentation mode of particles. Figure 4 shows the fragmentation process of one oil shale particle with laminated stucture. Such a particle is thin, and fragmentation initiation is anticipated at the side faces of the particle, which has the trend of forming more oil shale particles with laminated stucture.

Figure 2 also illustrates that thermal stress fragmentation and devolatilization-induced fragmentation have little effect on small-size particles $(<0.6 \mathrm{~mm})$ 


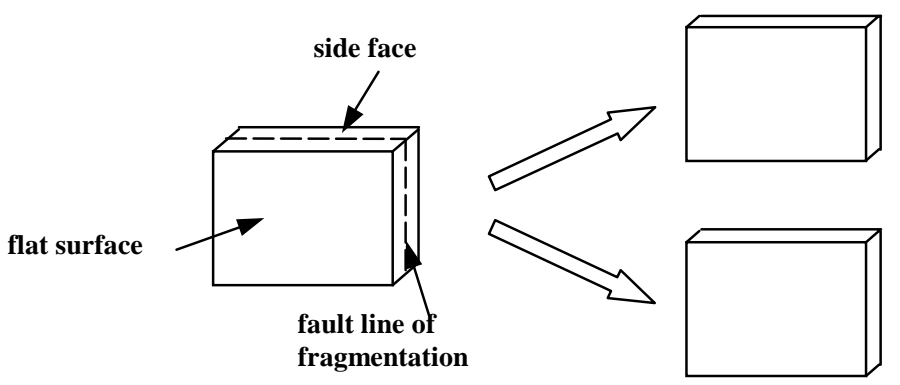

Fig. 4. The fragmentation process of one oil shale particle with laminated stucture.

because of uniform temperature distribution in little time and rapid mass transfer during devolatilization. Thus, the fragmentation on small particles may be mainly caused by secondary fragmentation and attrition during the later period of fluidized bed combustion [15]. It could be said that shale char particles $(<0.6 \mathrm{~mm})$ change little during the primary fragmentation.

\section{Neural network model}

Artificial neural networks (ANN) is a new information processing system modeling and spreading intellectual function of human. ANN are composed of a great deal of simple processing elements connected according to a certain rule, and are a non-linearity dynamic system with parallel calculation, distributed storage, self-adaption, self-learning and self-organization $[16,17]$. Over 50 different types of neural networks are set up to describe and model the biological neural system at different levels [18]. The most commonly employed neural networks for modeling steady-state systems is the 'feed forward' one, in which information is propagated in one direction only [19]. At present, the most extensively adopted algorithm for the learning phase is the Back Propagation (BP) one, which is a generalization of the steepest descent method [20,21]. The typical BP network consists of an input layer, an output layer and at least one hidden layer, as shown in Fig. 5. Each layer contains neurons and each neuron is a simple microprocessing element which receives and combines signals from many neurons via weighted connections and is connected to all the neurons in the next layer.

Suppose a set of training samples 'input-output pair $(x, y)$ ' is available, each neuron in the hidden layer and output layer first calculates the weighted sum of all interconnected signals from the previous layer, and then generates an output through its transfer function:

$$
i_{i}=x_{i}, h_{j}=f_{i, j}\left(\sum W_{i, j} i_{i}\right), \quad o_{k}=f_{j, k}\left(\sum W_{j, k} h_{j}\right),
$$

where $W_{i, j}$ and $W_{j, k}$ are the weights between two adjacent layers. 


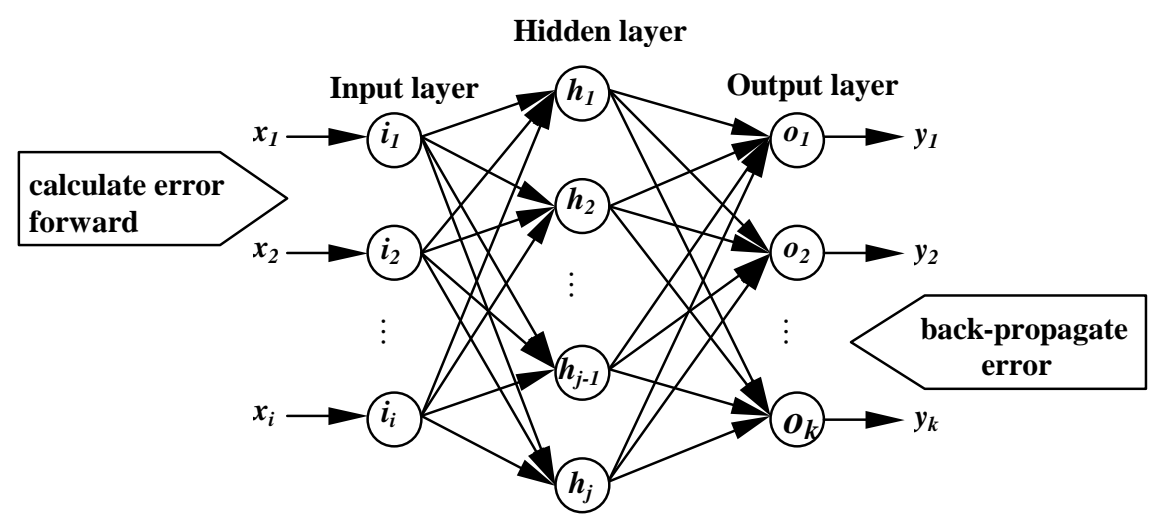

Fig, 5. Illustration of the structure of a BP network.

Next, the problem can be characterized as the process of minimizing the following sum of quadratic mean deviation $E_{p}$ :

$$
E_{p}=\frac{1}{2} \sum_{k}\left(o_{p k}-y_{p k}\right)^{2}, \quad E=\frac{1}{2 P} \sum_{p} \sum_{k}\left(o_{p k}-y_{p k}\right)^{2},
$$

where $P$ is the number of data pairs.

The weights are adjusted by back-propagating the error from the output layer to the input layer. Herein, the deferred adjustment is used, and the adjustment between the $(n)$ th and the $(n+1)$ th iterative is:

$$
\begin{gathered}
\Delta W_{i j}(n+1)=\eta \frac{\partial E_{p}}{\partial h_{p j}} h_{p j}+\Delta W_{i j}(n), \\
\Delta W_{k j}(n+1)=\eta \frac{\partial E_{p}}{\partial o_{p k}} o_{p k}+\Delta W_{k j}(n),
\end{gathered}
$$

where the positive constant $\eta$ is the learning rate.

In this work, a BP network model was used to analyze the primary fragmentation of Huadian oil shale particles operating in the turbulent fluidizing bed. The dimensions of input layer and output layer in the BP network structure are designed by the object that the particle size distribution of Huadian oil shale after primary fragmentation can be predicted at random temperature. That is to say, the fluidized-bed temperature is the input part and the particle size distribution after primary fragmentation is the output part. Thus, the input layer consists of one input neuron corresponding to different fluidized-bed temperature, the transfer function of which is tangent sigmoid transfer function (tansig). The output layer is composed of 13 output neurons corresponding to 13 sieve sizes $(0,0.6,0.8,1,2,3,4,5,6,7,8,10$, $12 \mathrm{~mm}$ ), the transfer function of which is linear transfer function 'purelin'. 
An important step in the modeling process is the determination of the adequate number of neurons in the hidden layer. Using too few neurons impairs the neural network and prevents the correct mapping of input to output. Using too many neurons impedes generalization and increases training time [22]. The optimal number of neurons in the hidden layer was determined by varying the number of hidden neurons and observing the root mean square error (RMS) between the experimental results and the calculated output of the BP network [23]. The number of neurons used for the hidden layer is optimized by trial-and-error training assays, and it is confirmed that choosing 12 hidden neurons can make the network model come to convergence in a short time. The transfer function of the hidden neurons is tansig.

A three-layer network model for primary fragmentation of oil shale particles has been set up. The input layer of the model has one neuron, the hidden layer has 12 neurons, and the output layer has 13 neurons. The BP neural network system can be trained by the following steps, shown in Fig. 6 . The learning rate of the network model is $10^{-4}$. In the first place, the actual outputs of the BP network are computed forward from the input layer to the output layer. While in the second place, the descent gradient is calculated in a back-propagation fashion, which makes it possible to adjust the weights in a descent direction. After presentation of the first input-output pair, the second pair is processed, and so on. Training is carried out by repeatedly presenting the entire set of training patterns until all error signals between the desired and actual outputs over all the training patterns are minimized and within the preset training precision $\left(10^{-9}\right.$ in this work). At each iteration, the weights between the hidden and output layers are adjusted first. Subsequently, the weights between the input and hidden layers are changed. Thus, the knowledge rules of the network model are trained in the process of network learning.

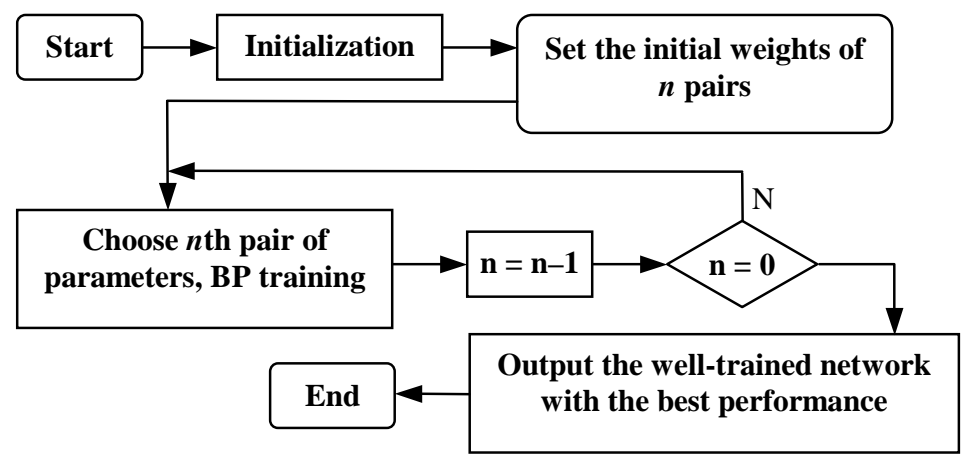

Fig. 6. Framework of training neural network using BP algorithm. 
In order to verify the validity of the network model, the experiment data at bed temperature of 600,750 and $1000{ }^{\circ} \mathrm{C}$ are used as check-up samples to compare with prediction results. The values and errors between them are listed in Table 2, showing that the prediction data agree with experimental data.

Table 2. Comparison between experimental data and network prediction results

\begin{tabular}{|c|c|c|r|r|r|r|r|r|r|}
\hline \multirow{2}{*}{$\begin{array}{c}\text { Subject, } \\
\text { mm }\end{array}$} & \multicolumn{3}{|c|}{$600{ }^{\circ} \mathrm{C}$} & \multicolumn{3}{c|}{$750{ }^{\circ} \mathrm{C}$} & \multicolumn{3}{c|}{$1000{ }^{\circ} \mathrm{C}$} \\
\cline { 2 - 10 } & $\begin{array}{c}\text { experi- } \\
\text { ment data, } \\
\text { wt\% }\end{array}$ & $\begin{array}{c}\text { predic- } \\
\text { tion data, } \\
\text { wt\% }\end{array}$ & error & $\begin{array}{c}\text { experi- } \\
\text { ment data, } \\
\text { wt\% }\end{array}$ & $\begin{array}{c}\text { predic- } \\
\text { tion data, } \\
\text { wt\% }\end{array}$ & error & $\begin{array}{c}\text { experi- } \\
\text { ment data, } \\
\text { wt\% }\end{array}$ & $\begin{array}{c}\text { predic- } \\
\text { tion data, } \\
\text { wt\% }\end{array}$ & error \\
\hline 0 & 100 & 100.0002 & 0.0002 & 100 & 100.0004 & 0.0004 & 100 & 100.0005 & 0.0005 \\
0.6 & 90.82 & 90.8196 & -0.0004 & 90.82 & 90.8191 & -0.0009 & 90.82 & 90.8193 & -0.0007 \\
0.8 & 85.661 & 85.6607 & -0.0003 & 85.294 & 85.2932 & -0.0008 & 83.896 & 83.9954 & 0.0994 \\
1 & 77.225 & 77.2245 & -0.0005 & 76.977 & 76.9754 & -0.0016 & 69.083 & 69.0818 & -0.0012 \\
2 & 49.253 & 49.2529 & -0.0001 & 48.309 & 48.3088 & -0.0002 & 45.653 & 45.6537 & 0.0007 \\
3 & 33.067 & 33.0763 & 0.0093 & 27.982 & 27.9821 & 0.0001 & 29.595 & 29.5954 & 0.0004 \\
4 & 18.413 & 18.4129 & -0.0001 & 18.853 & 18.8523 & 0.0007 & 15.026 & 15.0266 & 0.0006 \\
5 & 10.901 & 10.901 & 0 & 9.7996 & 9.7994 & -0.0002 & 8.4662 & 8.4663 & 0.0001 \\
6 & 5.7473 & 5.7479 & 0.0006 & 5.0145 & 5.0158 & 0.0013 & 5.9353 & 5.9364 & 0.0011 \\
7 & 3.1345 & 3.1347 & 0.0002 & 2.6359 & 2.6361 & 0.0002 & 2.2962 & 2.2967 & 0.0005 \\
8 & 1.5403 & 1.5399 & -0.0004 & 1.1139 & 1.1128 & -0.0011 & 0.5444 & 0.5437 & -0.0007 \\
10 & 0.45 & 0.4501 & 0.0001 & 0.45 & 0.4502 & 0.002 & 0.45 & 0.4592 & 0.0092 \\
12 & 0 & 0.0001 & 0.0001 & 0 & 0.0003 & 0.0003 & 0 & 0.0002 & 0.0002 \\
\hline
\end{tabular}

\section{Conclusions}

The experiment of the primary fragmentation of Huadian oil shale was conducted using a small-scale fluidized-bed reactor, and a Back Propagation network model for the primary fragmentation of oil shale has been set up through network learning. The prediction results from the BP network model agree with experimental data. The main conclusions are given below:

1) The experiment results indicate that the fluidized-bed temperature is an important factor of oil shale primary fragmentation, and that higher fluidized-bed temperature results in severer fragmentation.

2) The particle size distribution of both oil shale and its chars approximately submits R-R distribution. The laminated structure and high ash content may contribute to the primary fragmentation characteristics of Huadian oil shale.

3) The thermal stress fragmentation and devolatilization-induced fragmentation have little effect on small oil shale particles. It could be said that shale char particles $(<0.6 \mathrm{~mm})$ change little during primary fragmentation.

4) The Back Propagation network model for oil shale primary fragmentation can predict the particle size distribution of shale chars obtained at different fluidized-bed temperatures, which provides some references for the computation and design of fluidized bed boilers. 


\section{Acknowledgements}

This work was supported by the National High Technology Research and Development Program of China (863 Program) (Grant no. 2007AA05Z333)

\section{REFERENCES}

1. Jiang, X. M., Liu, D. C., Chen, H. P. et al. Experimental investigation on oil shale circulating fluidized bed boiler // Oil Shale. 2001. Vol. 18, No. 1. P. 7383.

2. Jiang, X. M., Han, X.X., Cui, Z. G. et al. Flow structure and combustion characteristic of $65 \mathrm{t} / \mathrm{h}$ oil shale-fired circulating fluidized bed riser. 1: Dense phase // Ind. Eng. Chem. Res. 2006. Vol. 45, No. 12. P. 4329-4334.

3. Han, X. X., Jiang, X. M., Cui, Z. G. Flow structure and combustion characteristic of $65 \mathrm{t} / \mathrm{h}$ oil shale-fired circulating fluidized bed riser 2: Dilute phase // Chem. Eng. Sci. 2006. Vol. 61, No. 8. P. 2533-2539.

4. Jiang, X. M., Han, X. X., Cui, Z. G. Progress and recent utilization trends in combustion of Chinese oil shale // Prog. Energy Combust. Sci. 2007. Vol. 33, No. 6. P. 552-575.

5. Arro, H., Prikk, A., Pihu, T. Calculation of $\mathrm{CO}_{2}$ emission from CFB boilers of oil shale power plants // Oil Shale. 2006. Vol. 23, No. 4. P. 356-365.

6. Chirone, R., Massimilla, $L$. Primary fragmentation in fluidized bed combustion of anthracites // Powder Technol. 1991. Vol. 64, No. 3. P. 249-258.

7. Stubington, J. F., Moss, B. On the timing of primary fragmentation during bituminous coal particle devolatilisation in a fluidized bed combustor // Can. J. Chem. Eng. 1995. Vol. 73, No. 4. P. 505-509.

8. Solomon, P. R., Serio, M. A., Carangelo, R. M., Markham, J. R. Very rapid coal pyrolysis // Fuel. 1986. Vol. 65, No. 2. P. 182-194.

9. Basu, P., Greenblatt, J. H., Basu, A. Studies of the fragmentation of different coals in a fluidized bed // J. Energ. Inst. 2005. Vol. 78, No. 1. P. 32-37.

10. Dacombe, P., Pourkashanian, M., Williams, A., Yap, L. Combustion-induced fragmentation behavior of isolated coal particles // Fuel. 1999. Vol. 78, No. 15. P. 1847-1857.

11. Lee, S. H., Kim, S. D., Lee, D. H. Particle size reduction of anthracite coals during devolatilization in a thermobalance reactor// Fuel. 2002. Vol. 81, No. 13. P. 1633-1639.

12. Dakič, D., Honing, G. V., Valk, M. Fragmentation and swelling of various coals during devolatilization in a fluidized bed // Fuel. 1989. Vol. 68, No. 7. P. 911916.

13. Abdelmounaim, B., Pierre, V.J. The impact of thermal pre-treatment on oil shale attrition and fragmentation in fluidized bed combustion // Exp. Therm. Fluid Sci. 2004. Vol. 28, No. 7. P. 677-682.

14. Al-Otoom, A. Y., Shawabkeh, R. A., Al-Harahsheh, A. M., Shawaqfeh, A. T. The chemistry of minerals obtained from the combustion of Jordanian oil shale // Energy. 2005. Vol. 30, No. 5. P. 611-619. 
15. Jiang, $X$. M. Study on combustion mechanism of oil shale circulating fluidized bed, Ph. D. dissertation. Harbin: Harbin Institute of Technology, 1998 [in Chinese].

16. Haykin, S. Neural Networks - A Comprehensive Foundation. - Toronto: Maxwell Macmillan Canada, 1994. P. 696.

17. Caudill, M., Butler, C. Naturally Intelligent Systems. - Cambridge: The MIT Press, 1990. P. 304.

18. Bulsari, A. B. (ed.) Neural Network for Chemical Engineers. - Amsterdam: Elsevier, 1995.

19. $\mathrm{Su}, H$. T., McAvoy, T. J., Werbos, $P$. Long-term predictions of chemical processes using recurrent neural networks. A parallel training approach // Ind. Eng. Chem. Res. 1992. Vol. 31, No. 5. P. 1338-1352.

20. Zhou, X. G., Liu, L. H., Dai, Y. C., Yuan, W. Modeling of a fixed-bed reactor using the K-L expansion and neural networks // Chem. Eng. Sci. 1996. Vol. 51, No. 10. P. 2179-2188.

21. Piron, E., Latrille, E., Rene, F. Application of artificial neural networks for crossflow microfiltration modelling: 'Black-box' and semi-physical approaches // Comput. Chem. Eng. 1997. Vol. 21, No. 9. P. 1021-1030.

22. Bailey, D., Thompson, D. How to develop neural-network applications // AI Expert. 1990. Vol. 5, No. 6. P. 38-47.

23. Pan, Y., Jiang, J. C., Wang, Z. R. Quantitative structure-property relationship studies for predicting flash points of alkanes using group bond contribution method with back-propagation neural network // J. Hazard. Mater. 2007. Vol. 147, No. 1-2. P. 424-430.

Presented by A. Ots

Received June 2, 2008 